\title{
Tumor necrosis factor-308 polymorphism with the risk and prognosis of non-Hodgkin lymphomas: a meta-analysis study
}

This article was published in the following Dove Press journal:

OncoTargets and Therapy

21 March 2016

Number of times this article has been viewed

\author{
Sicheng Gao'** \\ Guoqing Zhu',* \\ Yan Lin' \\ Xingliang Fan' \\ Pingan Qian' \\ Junfeng $\mathrm{Zhu}^{3}$ \\ Yongchun $\mathrm{Yu}^{\prime}$ \\ 'Central Laboratory, Shanghai \\ Municipal Hospital of Traditional \\ Chinese Medicine, Shanghai \\ University of Traditional Chinese \\ Medicine, ${ }^{2}$ Department of Clinical \\ Laboratory Medicine, Shanghai Tenth \\ People's Hospital, Tongji University, \\ ${ }^{3}$ Department of Hepatology, Shanghai \\ Municipal Hospital of Traditional \\ Chinese Medicine, Shanghai University \\ of Traditional Chinese Medicine, \\ Shanghai, People's Republic of China \\ *These authors contributed equally \\ to this work
}

Background: Tumor necrosis factor-308 (TNF-308) was implied to be associated with the development of non-Hodgkin lymphoma (NHL). The aim of this meta-analysis study was to investigate the association of TNF-308A polymorphism with the susceptibility to, and prognosis of, NHL.

Methods: PubMed, Web of Science, Elsevier, HighWire, Scopus, and Google Scholar were searched up to May 2015. The association of TNF-308 polymorphism with the risk of NHL and prognosis was assessed by odds ratio and hazard ratio, respectively.

Results: Overall, TNF-308G $>$ A polymorphism increased the risk of NHL, B-cell lymphomas (BCL), and T-cell lymphomas and decreased the risk of follicular lymphomas. In stratified analysis, increased risk of BCL and diffuse large B-cell lymphomas (DLBCL) were observed in Caucasians and population-based studies, whereas decreased risk of NHL, BCL, and DLBCL were detected in Asians and hospital-based studies. Furthermore, pooled results of 1,192 patients with NHL from five studies suggested that TNF-308A was correlated with shorter progressionfree survival and overall survival in patients with NHL, BCL, and DLBCL.

Conclusion: Current evidence indicated that TNF-308A polymorphism was significantly associated with the risk and prognosis of NHL. Future studies should further confirm these associations in other NHL subtypes and ethnicities.

Keywords: tumor necrosis factor, polymorphism, rs1800629, lymphomas, susceptibility, survival outcome

\section{Introduction}

Non-Hodgkin lymphoma (NHL) is a heterogeneous group of neoplasms, developing from B-cell, T-cell, and natural killer (NK)/T-cell, with various clinical and biological features. ${ }^{1}$ There were $\sim 355,900$ new cases and 191,400 deaths from NHL worldwide in $2008 .^{2}$ The numbers continued to increase with estimated 385,700 new cases and 199,700 deaths in 2012. ${ }^{3}$ Epidemiologic studies have examined the etiology of NHL, identifying smoking, alcohol use, infectious agents, family history of lymphoma, autoimmune disease, asthma, and radiation exposure as risk factors. ${ }^{1,4-6}$

Tumor necrosis factor-alpha (TNF- $\alpha$ ) is the activator of canonical pathway of nuclear factor kappa B and is associated with the process of cellular growth, differentiation, and apoptosis. ${ }^{7}$ It is also noted that TNF- $\alpha$ is involved in the pathogenesis of inflammatory, autoimmune, and malignant diseases. ${ }^{8}$ Accumulating evidence indicates that the variation in the promoter of TNF- $\alpha$ polymorphism (rs1800629) is correlated with the susceptibility to and progression and prognosis of NHL. ${ }^{9-11}$

The association between TNF-308G $>$ A and the risk of NHL was examined in the previous three reviews and meta-analyses. ${ }^{12-14}$ A previous study published in 2006
Correspondence: Yongchun Yu; Junfeng Zhu Municipal Hospital of Traditiona Chinese Medicine, Shanghai University of Traditional Chinese Medicine, No 274, Middle Zhijiang Road, Shanghai 20007I, People's Republic of China

Tel +86 I59 I933 439I;

+8621 56639828

Email yueyongchun88@I63.com; zhujftongling@sina.com (c) (1) (5) 2016 Gao et al. This work is published and licensed by Dove Medical Press Limited. The full terms of this license are available at https://www.dovepress.com/terms.php
and incorporate the Creative Commons Attribution - Non Commercial (unported, v3.0) License (http://creativecommons.org/licenses/by-nc/3.0/). By accessing the work you hereby accept the Terms. Non-commercial uses of the work are permitted without any further permission from Dove Medical Press Limited, provided the work is properly attributed. For permission hereby accept the Terms. Non-commercial uses of the work are permitted without any further permission from Dove Medions.
for commercial use of this work, please see paragraphs 4.2 and 5 of our Terms (https://www.dovepress.com/terms.php). 
pooled the data of eight studies from an International Lymphoma Epidemiology Consortium, ${ }^{12}$ which only examined patients with diffuse large B-cell lymphomas (DLBCL) and follicular lymphomas (FL) in Caucasians, the most common forms of NHL. ${ }^{15}$ In 2010, Skibola et al extended the previous study and examined the risk of TNF-308G $>$ A in NHL and other subtypes in different ethnicities. ${ }^{13}$ The recent study by Zhai et al further pooled the data of 18 studies and examined this association in a larger population. ${ }^{14}$

However, odds ratio (OR) was either estimated using unconditional logistic regression models in the previous two meta-analyses ${ }^{12,13}$ or only examined in additive model (A vs G) in the recent one. ${ }^{14}$ Besides, this association was merely analyzed in ethnicity subgroups in the previous metaanalyses without stratification by the source of controls. Moreover, the prognosis value of TNF-308A in patients with NHL had not been examined in the previous meta-analyses.

We, therefore, performed this meta-analysis, aiming to further evaluate the association between TNF-308G $>$ A and the susceptibility to NHL under five genetic models and exploring the potential difference among ethnicities and sources of controls, as well as its correlation with survival outcome in patients with NHL.

\section{Materials and methods Publication search}

The databases of PubMed, Web of Science, Elsevier, HighWire, Scopus, and Google Scholar were searched up to May 2015 using the following terms: "TNF-308G $>$ A polymorphism, rs1800629, or tumor necrosis factor-alpha" and "non-Hodgkin lymphomas, NHL, or lymphomas." Additional studies in the reference list of key articles and relevant reviews were also identified manually to further refine our research results. All the articles were retrieved independently by two researchers (S Gao and G Zhu).

\section{Selection criteria}

The articles included should meet the following criteria: 1) the study should be a case-control design; 2) the study should have investigated the association of TNF-308 with the risk of NHL or prognosis; 3) data should be available to calculate OR or hazard ratio (HR); and 4) subjects included in the study should not be a human immunodeficiency virus (HIV)-negative population. In addition, the data of the same population reported in more than one study should be used only once.

\section{Data extraction}

A standard data collection form was used to extract the relevant information by two investigators (S Gao and Y Lin) independently, which included the first author, year of publication, sample size, ethnicity, source of control, and the genotype distribution of cases and controls or HRs with corresponding $95 \%$ confidence intervals (CIs). If HR was not reported in the article, Engauge Digitizer Version 4.1 was used to estimate the HR and 95\% CI. The ethnicities were categorized as Caucasian or Asian, and the source of controls was categorized as population based or hospital based. Any discrepancies were discussed to reach an agreement.

\section{Statistical analysis}

For susceptibility analysis, Hardy-Weinberg equilibrium (HWE) of each study was assessed by chi-square test in controls with $P<0.05$, which was considered a departure from HWE. OR was used to measure the strength of the association between TNF-308G $>$ A and the risk of NHL. Pooled OR was assessed under the allelic (A vs G), dominant (AA/GA vs GG), recessive (AA vs GA/GG), homozygous (AA vs GG), and heterozygous models (GA vs GG). The heterogeneity among the studies was estimated by $Q$-test and $I^{2}$ value; if $I^{2}>50 \%$, which was considered significant heterogeneity, a random- or fixed-effect model was used. Subgroup analysis was implemented, which was stratified by ethnicity and the source of controls. When a large amount of heterogeneity was exhibited, meta-regression analysis or sensitivity analysis was performed to explore the source of heterogeneity. Funnel plots and Egger's test were applied to estimate the potential publication bias.

For survival outcome, HR with $95 \%$ CI was used to estimate the association between TNF-308A and prognosis in patients with NHL. The heterogeneity among studies was evaluated by $Q$-test and $I^{2}$ value. If $I^{2}>50 \%$, which was considered significant heterogeneity, a random- or fixedeffect model was employed. Sensitivity analysis was also conducted to examine the influence of single study on pooled estimate. Publication bias was evaluated by funnel plots and Egger's test.

All the analyses were implemented with Stata Version 11.0. $P<0.05$ was considered statistically significant, and all $P$-values were two sided.

\section{Results}

The titles and abstracts of 221 records from the databases and another 18 articles from the reference lists were screened for eligibility. Eventually, 17 articles met the abovementioned criteria, ${ }^{9,16-31}$ where nine studies were further excluded because of the following reasons: insufficient data in six articles, ${ }^{5,6,10,32-34}$ the subjects were HIV-positive patients, ${ }^{35}$ or studies focused on the risk of relapse (Figure 1). ${ }^{11}$ Among 


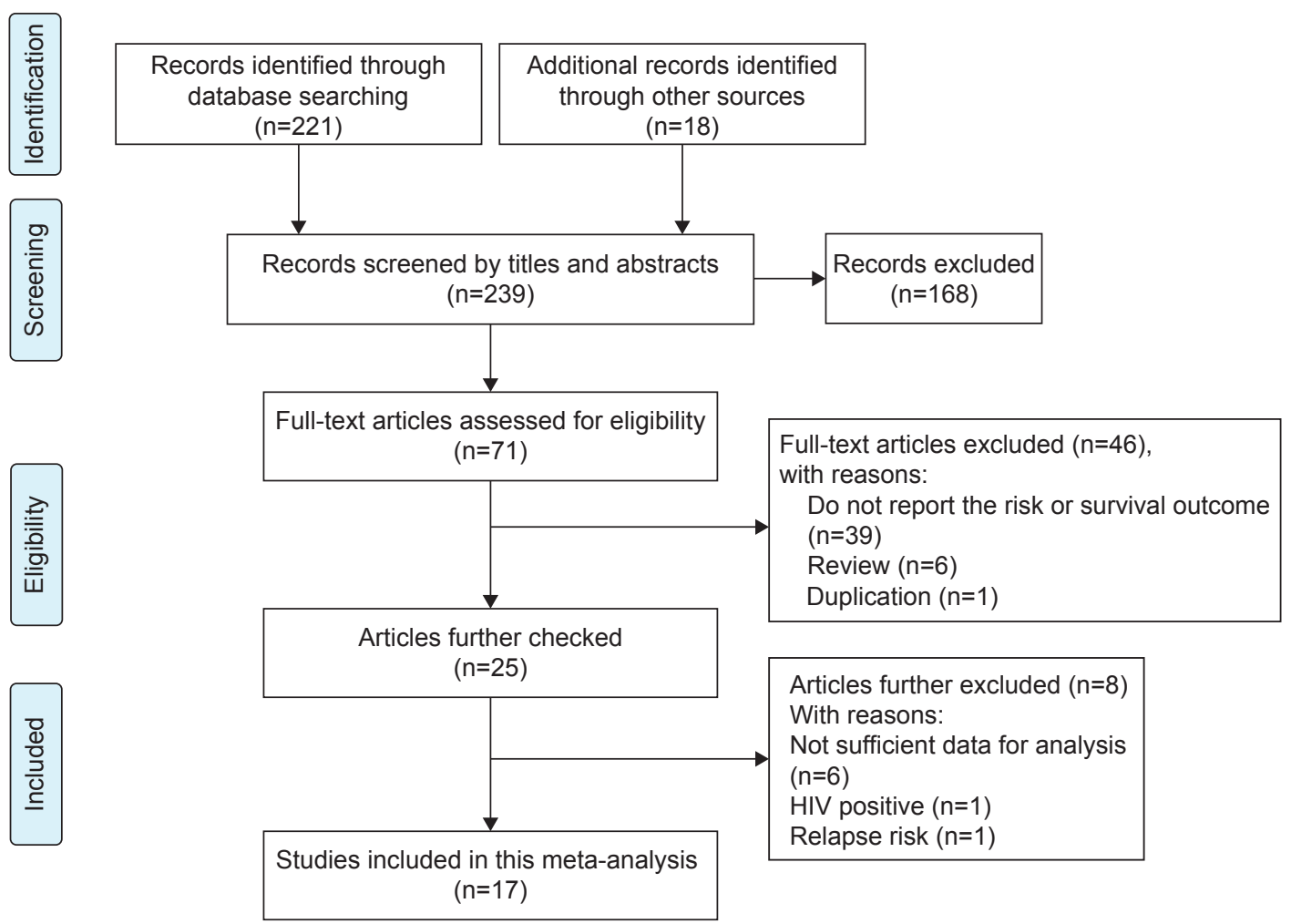

Figure I Flow diagram of the study selection process.

Abbreviation: HIV, human immunodeficiency virus.

the 17 pooled studies, 15 studies were used to analyze the association between TNF-308G $>$ A and the risk of NHL and five studies to investigate the prognostic values of TNF-308A in patients with NHL.

\section{Susceptibility analysis}

Characteristics of I5 pooled studies

A total of 15 eligible studies, which included 10,609 cases and 10,660 controls, were included to evaluate the association between TNF-308G $>$ A (rs1800629) and the genetic susceptibility to NHL. ${ }^{9,16-29}$ Of these, there were eleven studies of Caucasian descendants and four studies of Asian descendants. The source of controls was population based in eleven studies and hospital based in another four studies. None of the genotype distributions in control groups were deviated from HWE. The characteristics of 15 pooled studies are summarized in Table 1.

\section{TNF-308G $>$ A polymorphism and overall risk of $\mathrm{NHL}$}

Among the enrolled 10,609 NHL cases and 10,660 controls, significantly increased risks were observed in recessive genetic (AA vs GA/GG, OR =1.42, 95\% CI: 1.021-1.974, $P=0.037$; Figure 2) and homozygous models (AA vs GG, $\mathrm{OR}=1.434,95 \% \mathrm{CI}: 1.017-2.021, P=0.04)$ when all the eligible data were pooled together (Table 2). In the stratification analysis by ethnicity, consistent results were detected in allelic (A vs $\mathrm{G}, \mathrm{OR}=1.148,95 \% \mathrm{CI}$ : 0.007-1.309, $P=0.039$ ), homozygous (AA vs $\mathrm{GG}, \mathrm{OR}=1.591,95 \% \mathrm{CI}$ : 1.098-2.306, $P=0.014$ ), and recessive models (AA vs GA/ $\mathrm{GG}, \mathrm{OR}=1.564,95 \% \mathrm{CI}: 1.094-2.236, P=0.014)$ in Caucasians. However, the risk was reduced under heterozygous model (GA vs GG, OR $=0.816$, 95\% CI: 0.704-0.947, $P=0.007$; Figure $3 \mathrm{~A})$. In the subgroup analysis based on the source of controls, the risk was only reduced in hospitalbased studies when GA genotype was compared with GG genotype $(\mathrm{OR}=0.838,95 \% \mathrm{CI}$ : 0.732-0.961, $P=0.011$; Figure 3B).

TNF-308G $>$ A polymorphism and the risk of B-cell lymphomas and its subtypes

TNF-308G $>$ A was associated with significantly increased risk of B-cell lymphomas (BCL) in recessive (AA vs GA/GG, $\mathrm{OR}=1.498,95 \% \mathrm{CI}: 1.038-2.163, P=0.031)$ and homozygous models (AA vs GG, OR $=1.518,95 \% \mathrm{CI}$ : 1.035-2.225, $P=0.033$; Table 2). When stratified by ethnicity, a statistically significant association between TNF-308G $>$ A and the increased risk of BCL was observed in Caucasians under recessive (AA vs $\mathrm{GA} / \mathrm{GG}, \mathrm{OR}=1.581,95 \% \mathrm{CI}$ : 1.051-2.377, $P=0.028$ ) and homozygous models (AA vs $\mathrm{GG}, \mathrm{OR}=1.611$, 
Table I Characteristics of 15 pooled studies evaluating the association between TNF-308G $>$ A polymorphism and the risk of NHL

\begin{tabular}{|c|c|c|c|c|c|c|c|c|c|c|}
\hline \multirow[t]{2}{*}{ References } & \multirow[t]{2}{*}{ Year } & \multirow[t]{2}{*}{ Ethnicity } & \multirow[t]{2}{*}{ Source } & \multicolumn{7}{|c|}{ Genotype distribution (case/control) } \\
\hline & & & & GG & AG & AA & GG & AG & AA & HWE \\
\hline Osman et al ${ }^{9}$ & 2009 & Caucasian & $\mathrm{HB}$ & 59 & 34 & 1 & 79 & 51 & 9 & 0.26 \\
\hline Bel et $\mathrm{a}^{16}$ & 2006 & Caucasian & PB & 107 & 49 & 4 & 120 & 59 & 15 & 0.84 \\
\hline Nasiri et al ${ }^{17}$ & 2013 & Caucasian & $\mathrm{PB}$ & 105 & 22 & 2 & 58 & 9 & I & 0.8 \\
\hline Cerhan et $\mathrm{al}^{18}$ & 2008 & Caucasian & $\mathrm{HB}$ & 332 & 129 & 9 & 304 & 117 & 18 & 0.68 \\
\hline Liu et al $^{19}$ & 2013 & Asian & $\mathrm{HB}$ & 260 & 40 & 0 & 264 & 27 & 0 & 0.47 \\
\hline Juszczynski et a ${ }^{20}$ & 2002 & Caucasian & PB & 85 & 32 & 3 & 151 & 49 & 4 & $\mathrm{I}$ \\
\hline Warzocha et al ${ }^{21}$ & 1998 & Caucasian & PB & 69 & 24 & 3 & 203 & 65 & 5 & 1 \\
\hline Xiao and Zhang ${ }^{22}$ & 2010 & Asian & PB & 174 & 35 & 5 & 138 & 20 & 2 & 0.16 \\
\hline Hosgood et al ${ }^{23}$ & 2013 & Asian & $\mathrm{HB}$ & 3,091 & 506 & 25 & I,702 & 221 & 9 & 0.69 \\
\hline Gu et $\mathrm{al}^{24}$ & 2014 & Asian & PB & 186 & 40 & 5 & 49 & 12 & 3 & 0.29 \\
\hline Gu et $\mathrm{a}^{24}$ & 2014 & Asian & PB & 190 & 14 & 0 & 78 & 13 & 0 & 0.88 \\
\hline Fernberg et $\mathrm{al}^{25}$ & 2010 & Caucasian & $\mathrm{PB}$ & $\mathrm{I}, 007$ & 431 & 46 & $\mathrm{I}, 490$ & 675 & 102 & 1 \\
\hline Spink et a ${ }^{26}$ & 2006 & Caucasian & PB & 590 & 312 & 44 & 627 & 317 & 40 & 0.95 \\
\hline Ibrahima et $\mathrm{al}^{27}$ & 2012 & Caucasian & PB & 67 & 27 & 6 & 41 & 21 & 22 & 0.38 \\
\hline Morton et $\mathrm{a}^{28}$ & 2008 & Caucasian & PB & 696 & 207 & 18 & 799 & 298 & 38 & 0.85 \\
\hline Purdue et $\mathrm{al}^{29}$ & 2007 & Caucasian & $\mathrm{PB}$ & 318 & 143 & 21 & 345 & 164 & 25 & 0.63 \\
\hline
\end{tabular}

Abbreviations: HB, hospital based; HWE, Hardy-Weinberg equilibrium; NHL, non-Hodgkin lymphoma; PB, population based; TNF, tumor necrosis factor.

95\% CI: $1.054-2.496, P=0.028$; Table 2). Conversely, there was a significant lower risk in Asians under heterozygous model (GA vs GG, OR =0.799, 95\% CI: 0.669-0.954, $P=0.013$; Figure 4A). In the stratified analysis by the source of controls, a significant increased risk of BCL was found in population-based studies under the allelic model (A vs G, $\mathrm{OR}=1.2,95 \% \mathrm{CI}$ : $1.003-1.437, P=0.047)$, whereas decreased risk was found in hospital-based studies under heterozygous model (GA vs GG, OR =0.832, 95\% CI: 0.751-0.967, $P=0.017$; Figure 4B).

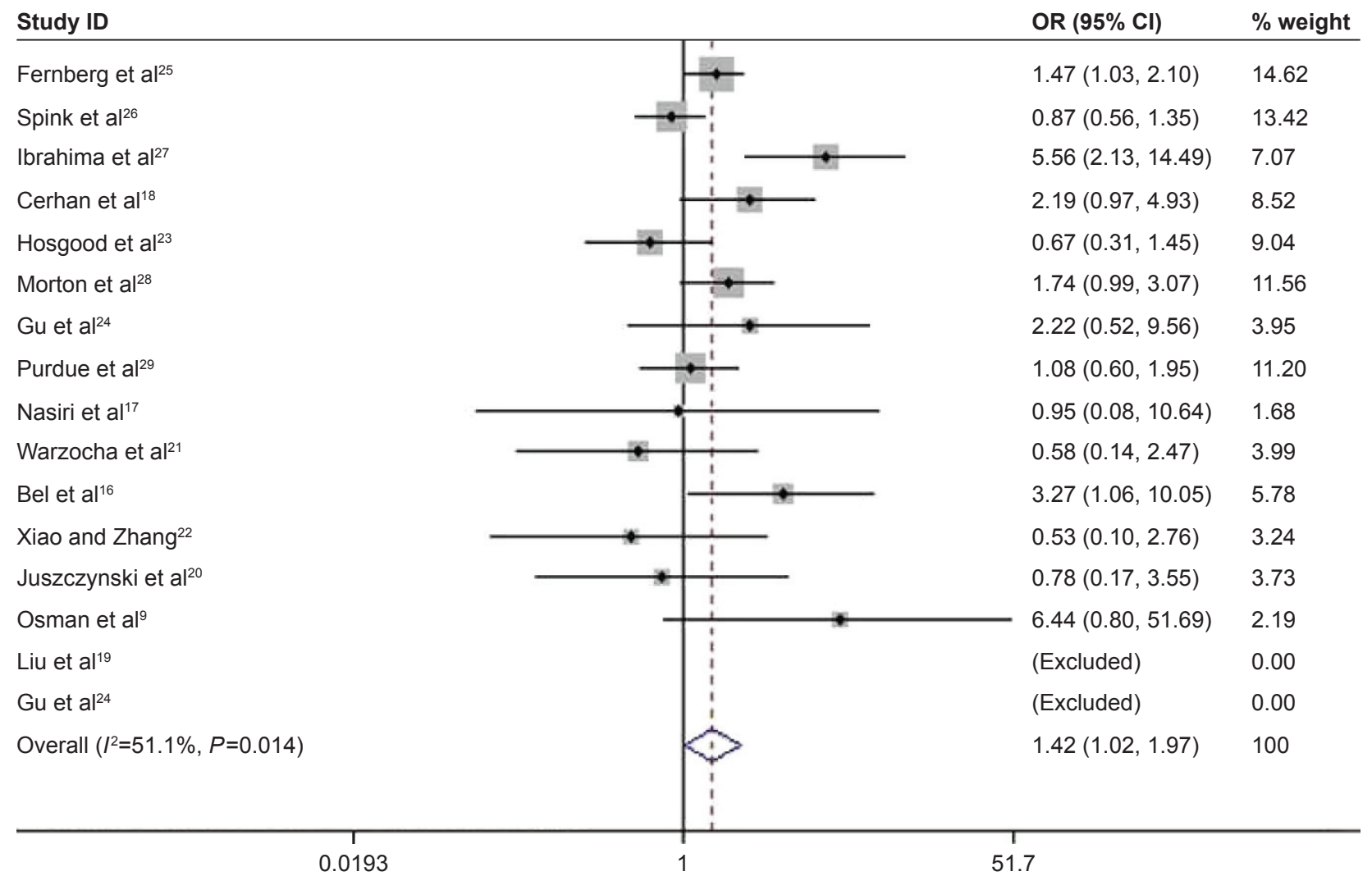

Figure 2 Association between TNF-308G $>$ A polymorphism and the risk of NHL in recessive model.

Note: Weights are from random effects analysis.

Abbreviations: $\mathrm{Cl}$, confidence interval; NHL, non-Hodgkin lymphoma; OR, odds ratio; TNF, tumor necrosis factor. 


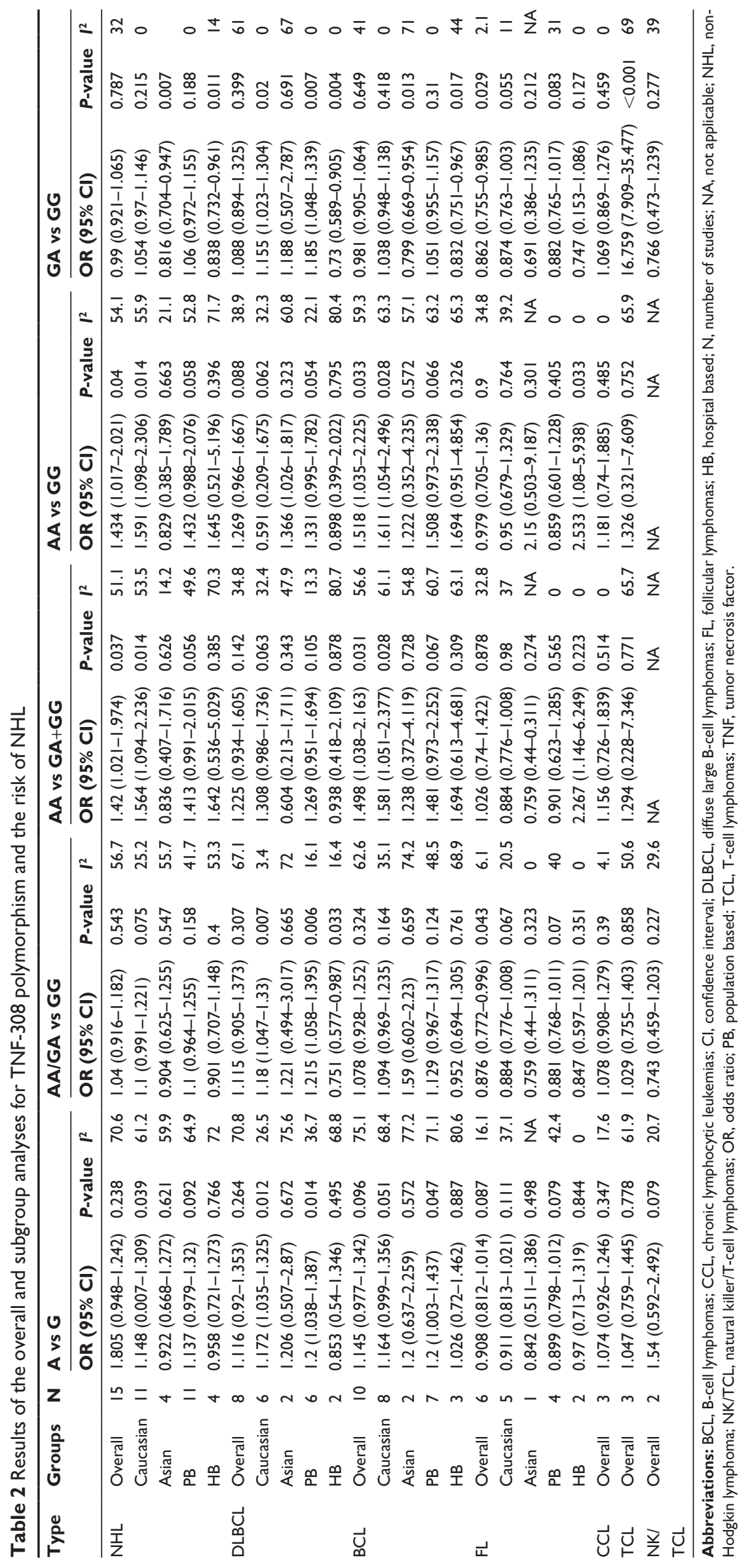


A Study ID

Caucasians

Fernberg et al ${ }^{25}$

Spink et $\mathrm{al}^{26}$

Ibrahima et $\mathrm{al}^{27}$

Cerhan et $\mathrm{al}^{18}$

Morton et $\mathrm{al}^{28}$

Purdue et $\mathrm{al}^{29}$

Nasiri et al ${ }^{17}$

Warzocha et $\mathrm{al}^{21}$

Bel et al $^{16}$

Juszczynski et al ${ }^{20}$

Osman et al ${ }^{9}$

Subtotal $\left(I^{2}=0.0 \%, P=0.834\right)$

\section{Asians}

Hosgood et $\mathrm{al}^{23}$

Liu et $\mathrm{al}^{19}$

Gu et $\mathrm{al}^{24}$

Gu et $\mathrm{al}^{24}$

Xiao and Zhang ${ }^{22}$

Subtotal $\left(I^{2}=49.7 \%, P=0.093\right)$

Overall $\left(I^{2}=32.4 \%, P=0.103\right)$

OR $(95 \% \mathrm{CI})$

$\%$ weight

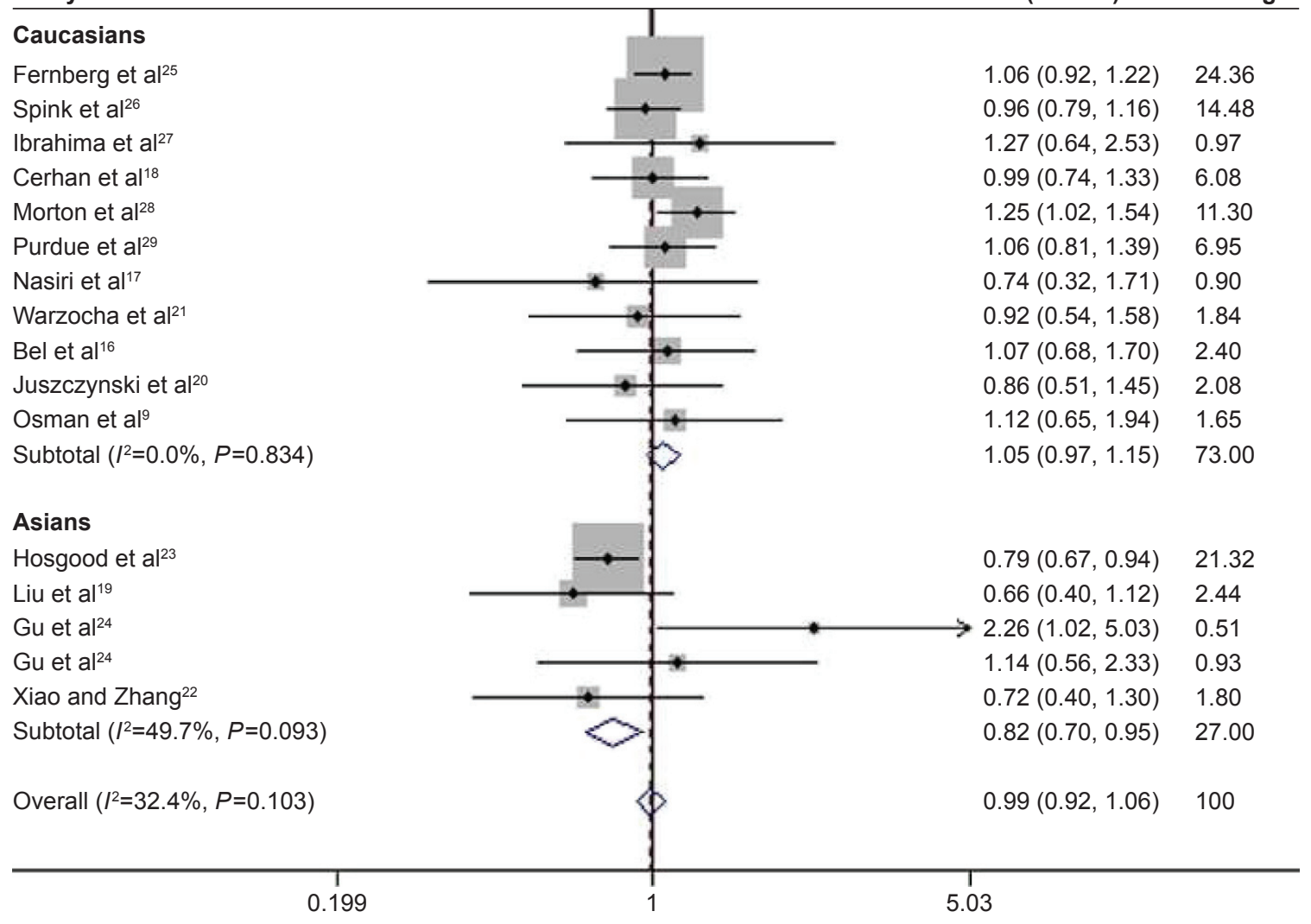

\section{B Study ID}

\section{PB}

Fernberg et $\mathrm{al}^{25}$

Spink et $\mathrm{al}^{26}$

Ibrahima et $\mathrm{al}^{27}$

Morton et $\mathrm{al}^{28}$

Gu et $\mathrm{al}^{24}$

Gu et al ${ }^{24}$

Purdue et $\mathrm{al}^{29}$

Nasiri et al ${ }^{17}$

Warzocha et al ${ }^{21}$

Bel et al ${ }^{16}$

Xiao and Zhang ${ }^{22}$

Juszczynski et al ${ }^{20}$

Subtotal $\left(I^{2}=0.0 \%, P=0.472\right)$

HB

Cerhan et $\mathrm{al}^{18}$

Hosgood et $\mathrm{al}^{23}$

Liu et al ${ }^{19}$

Osman et $\mathrm{al}^{9}$

Subtotal $\left(I^{2}=13.9 \%, P=0.323\right)$

Overall $\left(I^{2}=32.4 \%, P=0.103\right)$

$1.06(0.92,1.22) \quad 24.36$

$0.96(0.79,1.16) \quad 14.48$

$0.99(0.74,1.33) \quad 6.08$

$1.25(1.02,1.54) \quad 11.30$

$1.06(0.81,1.39) \quad 6.95$

$0.74(0.32,1.71) \quad 0.90$

$0.92(0.54,1.58) \quad 1.84$

$1.12(0.65,1.94) \quad 1.65$

$1.05(0.97,1.15) \quad 73.00$

$0.79(0.67,0.94) \quad 21.32$

$0.66(0.40,1.12) \quad 2.44$

$1.14(0.56,2.33) \quad 0.93$

$0.72(0.40,1.30) \quad 1.80$

$0.82(0.70,0.95) \quad 27.00$

0.199

OR $(95 \% \mathrm{Cl}) \quad \%$ weight

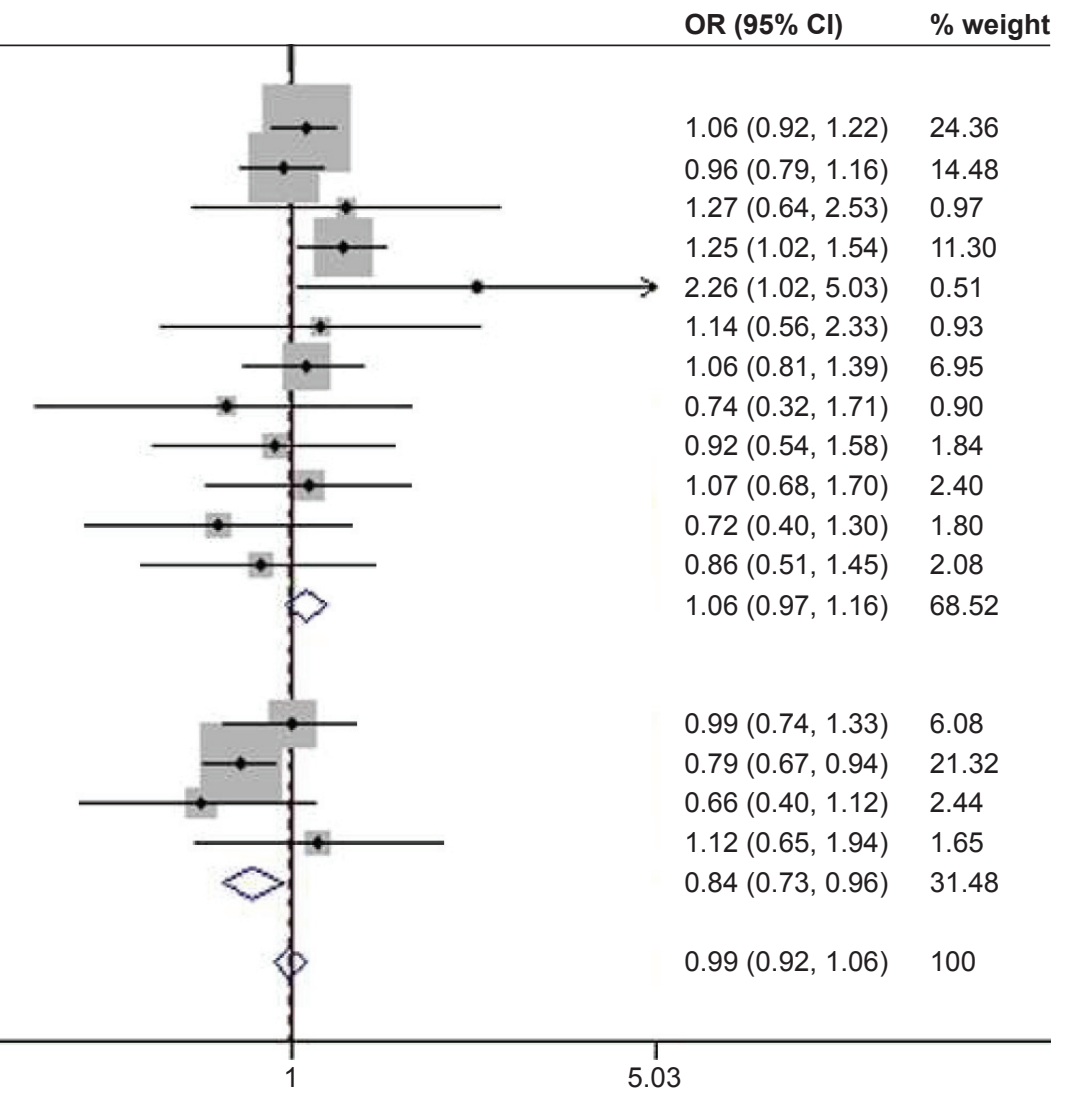

Figure 3 Association between TNF-308G > A polymorphism and the risk of NHL in heterozygous model.

Notes: (A) Stratified by ethnicity. (B) Stratified by the source of control.

Abbreviations: $\mathrm{Cl}$, confidence interval; $\mathrm{HB}$, hospital based; $\mathrm{NHL}$, non-Hodgkin lymphoma; OR, odds ratio; PB, population based; TNF, tumor necrosis factor. 
A Study ID

OR $(95 \% \mathrm{Cl})$

$\%$ weight

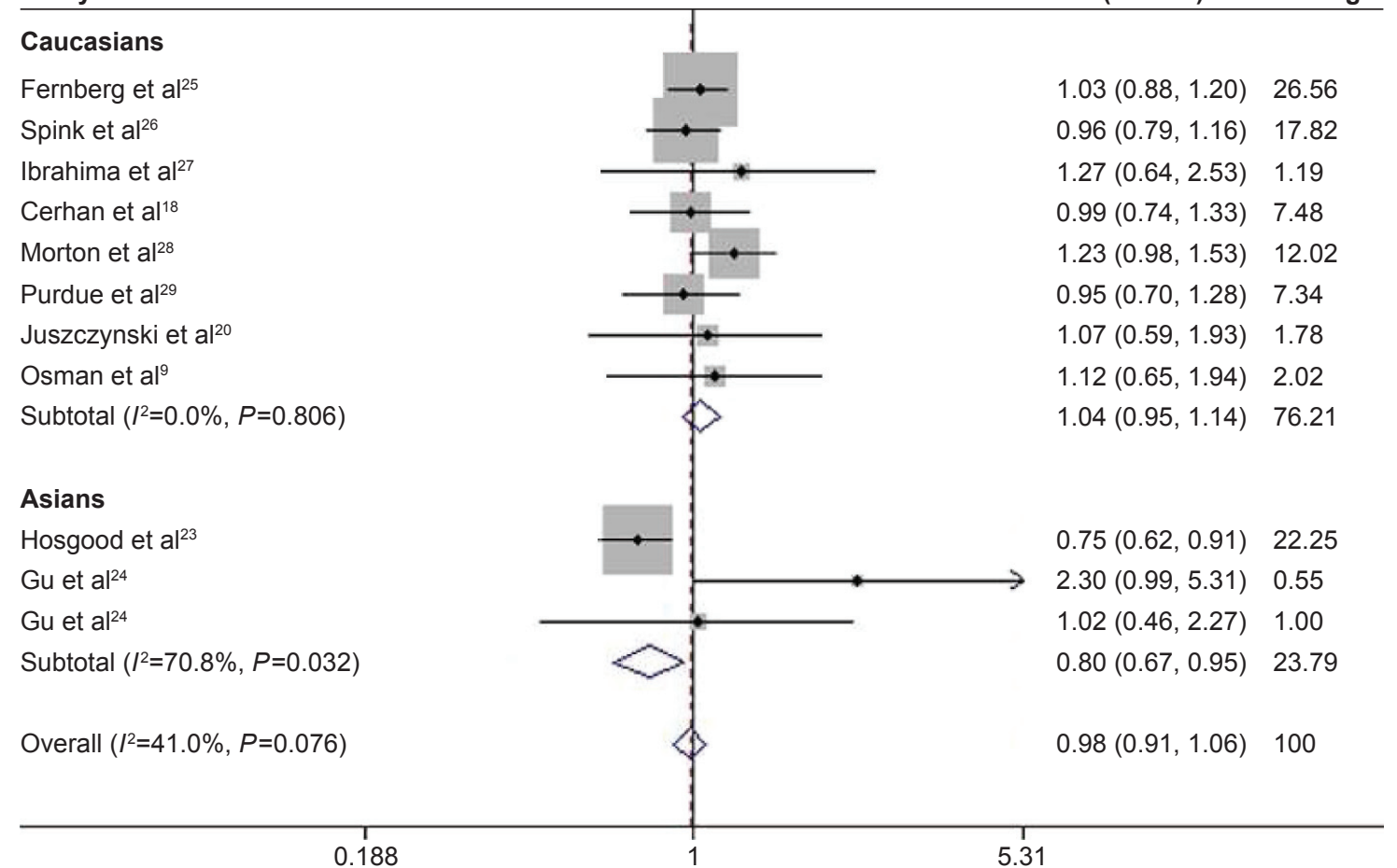

B Study ID

OR $(95 \% \mathrm{Cl}) \quad \%$ weight

PB

Fernberg et $\mathrm{a}^{25}$

Spink et $\mathrm{al}^{26}$

Ibrahima et $\mathrm{al}^{27}$

Morton et $\mathrm{al}^{28}$

Gu et $\mathrm{al}^{24}$

Gu et $\mathrm{al}^{24}$

Purdue et $\mathrm{al}^{29}$

Juszczynski et al ${ }^{20}$

Subtotal $\left(I^{2}=0.0 \%, P=0.432\right)$

HB

Cerhan et al ${ }^{18}$

Hosgood et al ${ }^{23}$

Osman et al ${ }^{9}$

Subtotal $\left(I^{2}=44.2 \%, P=0.167\right)$

Overall $\left(I^{2}=41.0 \%, P=0.076\right)$

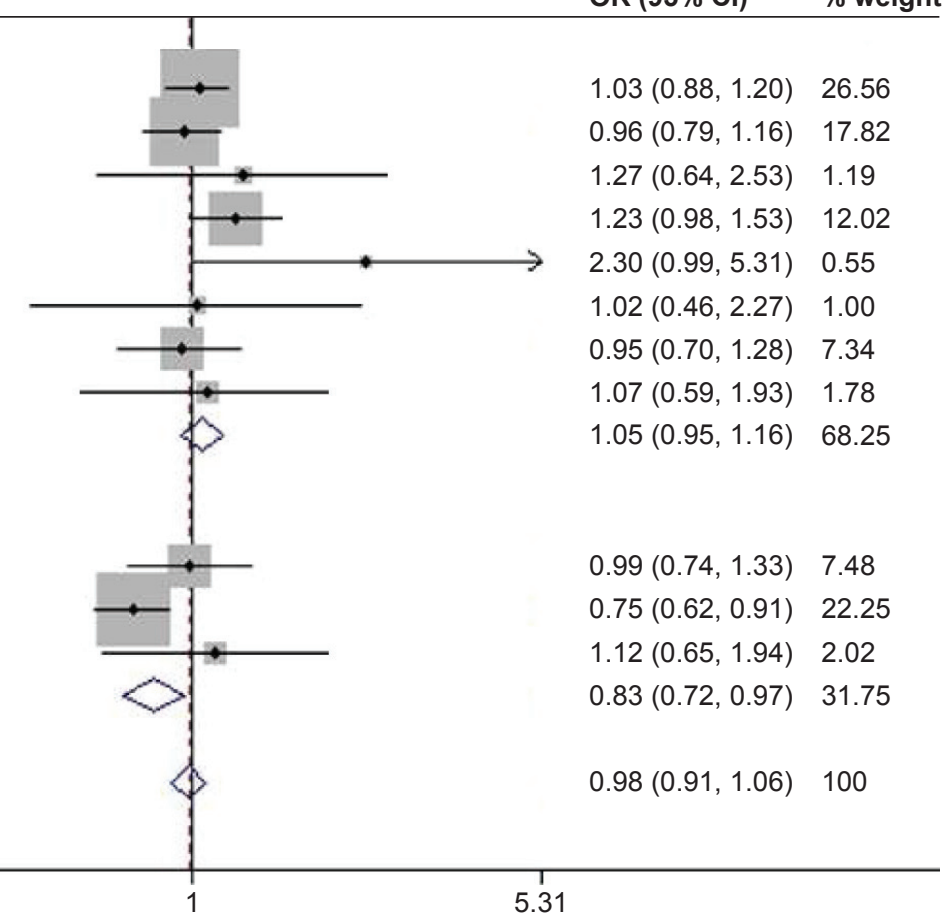

Figure 4 Association between the risk of BCL and TNF-308G > A polymorphism in heterozygous model.

Notes: (A) Stratified by ethnicity. (B) Stratified by the source of control.

Abbreviations: $\mathrm{BCL}$, B-cell lymphomas; Cl, confidence interval; HB, hospital based; OR, odds ratio; PB, population based; TNF, tumor necrosis factor.

There was no significant association between TNF308G $>$ A polymorphism and the susceptibility to DLBCL, when all the data of DLBCL were pooled together. This association was only identified in Caucasians under the allelic (A vs G, OR $=1.172,95 \%$ CI: $1.035-1.325, P=0.012$ ), dominant (AA/GA vs GG, OR $=1.18,95 \%$ CI: $1.047-1.33$, $P=0.007$ ), and heterozygous models (GA vs GG, $\mathrm{OR}=1.155$, 95\% CI: 1.023-1.304, $P=0.02$; Figure 5A and Table 2). 
A Study ID

Caucasians

Fernberg et $\mathrm{al}^{25}$

Spink et $\mathrm{al}^{26}$

Cerhan et $a^{18}$

Morton et $\mathrm{al}^{28}$

Purdue et $\mathrm{al}^{29}$

Juszczynski et $\mathrm{al}^{20}$

Subtotal $\left(I^{2}=0.0 \%, P=0.497\right)$

Asians

Hosgood et $\mathrm{al}^{23}$

Gu et $\mathrm{al}^{24}$

Gu et $\mathrm{al}^{24}$

Subtotal $\left(I^{2}=67.1 \%, P=0.048\right)$

Overall $\left(I^{2}=60.6 \%, P=0.009\right)$
OR $(95 \% \mathrm{Cl})$

$\%$ weight

$1.09(0.88,1.35) \quad 17.78$

$1.10(0.88,1.37) \quad 17.42$

$0.84(0.46,1.53) \quad 7.28$

$1.45(1.10,1.92) \quad 15.46$

$1.24(0.85,1.80) \quad 12.39$

$1.07(0.59,1.93) \quad 7.40$

$1.16(1.02,1.30) \quad 77.73$

$0.71(0.57,0.90) \quad 17.17$

$1.36(0.37,5.00) \quad 2.07$

$2.54(0.89,7.26) \quad 3.03$

$1.19(0.51,2.79) \quad 22.27$

$1.09(0.89,1.33) \quad 100$

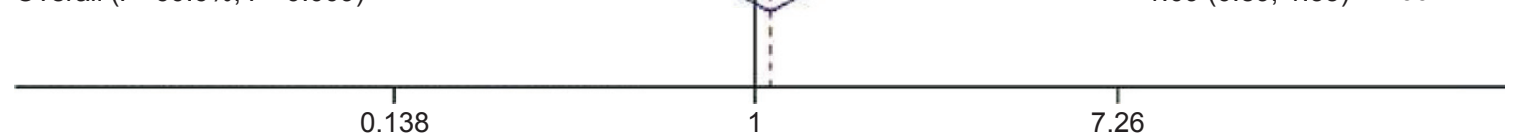

B Study ID

\section{PB}

Fernberg et $\mathrm{al}^{25}$

Spink et $\mathrm{al}^{26}$

Morton et $\mathrm{al}^{28}$

Gu et $\mathrm{al}^{24}$

Gu et $\mathrm{al}^{24}$

Purdue et $\mathrm{al}^{29}$

Juszczynski et al ${ }^{20}$

Subtotal $\left(I^{2}=0.0 \%, P=0.502\right)$

HB

Cerhan et $\mathrm{al}^{18}$

Hosgood et al ${ }^{23}$

Subtotal $\left(I^{2}=0.0 \%, P=0.621\right)$

Overall $\left(I^{2}=60.6 \%, P=0.009\right)$
OR $(95 \% \mathrm{Cl}) \quad \%$ weight

$1.09(0.88,1.35) \quad 17.78$

$1.10(0.88,1.37) \quad 17.42$

$1.45(1.10,1.92) \quad 15.46$

$1.36(0.37,5.00) \quad 2.07$

$2.54(0.89,7.26) \quad 3.03$

$1.24(0.85,1.80) \quad 12.39$

$1.07(0.59,1.93) \quad 7.40$

$1.18(1.05,1.34) \quad 75.55$

$0.84(0.46,1.53) \quad 7.28$

$0.71(0.57,0.90) \quad 17.17$

$0.73(0.59,0.90) \quad 24.45$

$1.09(0.89,1.33) \quad 100$

\begin{tabular}{lll|l}
\hline & & \\
\hline & 0.138 & 1 & 7.26
\end{tabular}

Figure 5 Association between the risk of DLBCL and TNF-308G $>$ A polymorphism in heterozygous model.

Notes: (A) Stratified by ethnicity. (B) Stratified by the source of control. Weights are from random effects analysis.

Abbreviations: $\mathrm{Cl}$, confidence interval; DLBCL, diffuse large B-cell lymphomas; HB, hospital based; OR, odds ratio; PB, population based; TNF, tumor necrosis factor.

When stratified by the source of controls, the risk was increased in population-based studies under allelic (A vs $\mathrm{G}$, $\mathrm{OR}=1.2,95 \%$ CI: $1.038-1.387, P=0.014$ ), dominant (AA/ GA vs GG, OR $=1.215,95 \%$ CI: $1.058-1.395, P=0.006)$, and heterozygous models (GA vs GG, OR $=1.185,95 \% \mathrm{CI}$ :
$1.048-1.339, P=0.007)$, while it was decreased in hospitalbased studies under dominant (AA/GA vs GG, OR $=0.751$, 95\% CI: $0.577-0.987, P=0.033)$ and heterozygous models (GA vs GG, OR $=0.73,95 \%$ CI: $0.589,0.905, P=0.004$; Figure 5B and Table 2). 


\begin{tabular}{|c|c|c|c|}
\hline Study ID & & OR $(95 \% \mathrm{Cl})$ & $\%$ weight \\
\hline Fernberg et $\mathrm{al}^{25}$ & + & $10.37(6.54,16.45)$ & 47.32 \\
\hline Hosgood et al ${ }^{23}$ & & $23.26(14.26,37.95)$ & 46.30 \\
\hline Liu et $\mathrm{al}^{19}$ & & $54.17(3.29,892.67)$ & 6.38 \\
\hline Overall $\left(P^{2}=69.2 \%, P=0.039\right)$ & & $16.75(7.91,35.48)$ & 100 \\
\hline 0.00112 & & 93 & \\
\hline
\end{tabular}

Figure 6 Association between the risk of FL and TNF-308G $>$ A polymorphism in homozygous model.

Note: Weights are from random effects analysis.

Abbreviations: $\mathrm{Cl}$, confidence interval; FL, follicular lymphomas; OR, odds ratio; TNF, tumor necrosis factor.

Pooled results from six studies showed that people with TNF-308 $>$ A polymorphism had a decreased risk of FL under dominant (AA/GA vs GG, OR $=0.876,95 \%$ CI: 0.772-0.996, $P=0.043$; Figure 6) and heterozygous models (GA vs GG, OR $=0.862,95 \%$ CI: $0.755-0.985, P=0.029$ ). However, no significant association between TNF-308G $>$ A polymorphism and the risk of FL was observed when stratified by ethnicity. Further subgroup analysis based on the source of controls indicated that the risk of FL was only increased in hospital-based studies under homozygous model (AA vs GG, $\mathrm{OR}=2.533,95 \%$ CI: $1.08-5.938, P=0.033$; Table 2 ).

Based on the results of three studies, there was no significant association between TNF-308G $>$ A polymorphism and the susceptibility to chronic lymphocytic leukemia (Table 2).

TNF-308G $>$ A polymorphism and the risk of T-cell lymphomas and NK/T-cell lymphomas

The pooled results of three studies indicated that a significantly increased risk of T-cell lymphomas (TCL) was observed, when GA genotype was compared with GG genotype $(\mathrm{OR}=16.759,95 \% \mathrm{CI}$ : 7.909-35.477, $P<0.001$; Figure 7). There were no significant correlations between TNF-308G $>$ A and the risk of NK/TCL based on the data of two studies.

\section{Evaluation of heterogeneity and publication bias}

There were some heterogeneities in the outcomes of overall NHL, BCL, DLBCL, and TCL. We performed subgroup analysis and meta-regression to investigate the sources of heterogeneity among studies. As shown earlier, the heterogeneity was decreased in some of the outcomes after the stratification of ethnicity and source of controls (Table 2). Furthermore, ethnicity (allelic model, $P=0.044$; recessive model, $P=0.029)$ and publication years (recessive model, $P=0.039)$ were identified as the sources of heterogeneity based on the results of meta-regression. Therefore, the publication year, ethnicity, and source of controls all may contribute to the heterogeneity exhibited in this meta-analysis. Sensitivity analysis was also performed, and the studies of

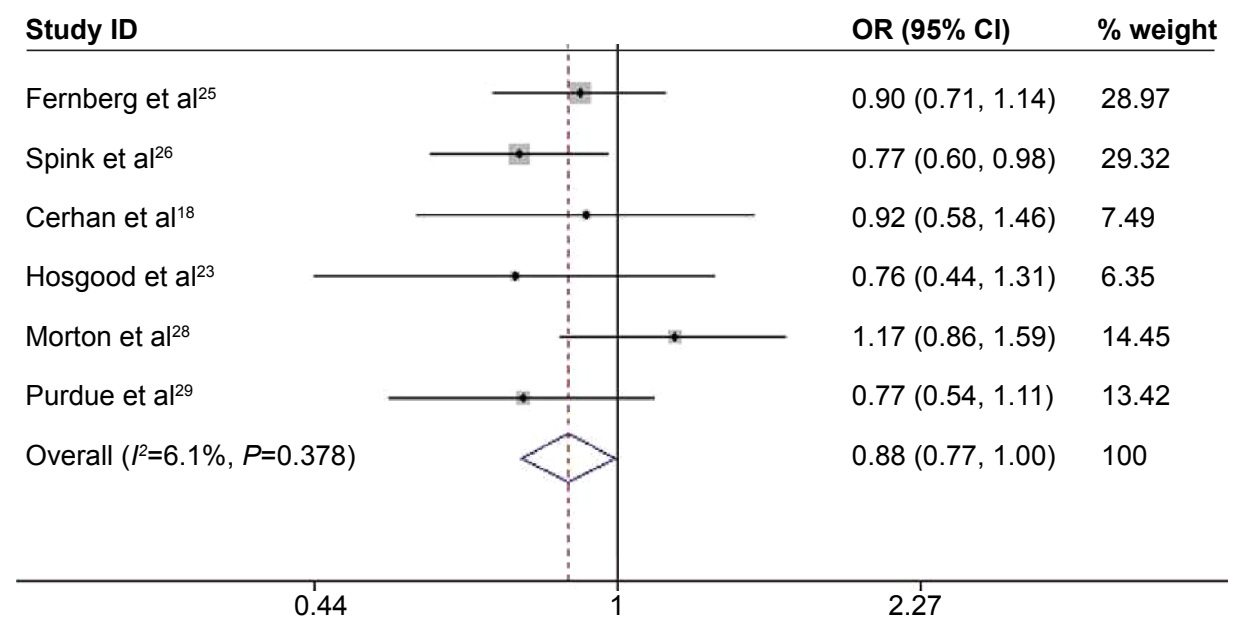

Figure 7 Association between the risk of TCL and TNF-308G $>$ A polymorphism in homozygous model. 
Table 3 Characteristics of five pooled studies evaluating the correlation between TNF-308 and the survival outcome in patients with NHL

\begin{tabular}{|c|c|c|c|c|c|c|c|c|}
\hline References & Year & Ethnicity & Case (n) & Control (n) & Type & Outcome & HR (95\% Cl) & Risk factor \\
\hline Osman et al ${ }^{9}$ & 2009 & Caucasian & 60 & 79 & $\mathrm{BCL}$ & PFS & $6.5(1.9830,21.3059)$ & TNF-308A \\
\hline \multirow[t]{4}{*}{ Juszczynski et a ${ }^{20}$} & 2002 & Caucasian & 53 & $15 \mid$ & $\mathrm{NHL}$ & PFS & $1.63(1.4155,1.877)$ & TNF-308A \\
\hline & & Caucasian & 53 & $15 \mid$ & $\mathrm{NHL}$ & OS & $1.51(1.3557,1.6819)$ & TNF-308A \\
\hline & & Caucasian & 32 & 72 & DLBCL & PFS & $1.52(1.2893,1.7920)$ & TNF-308A \\
\hline & & Caucasian & 32 & 72 & DLBCL & OS & $1.43(1.2442,1.6435)$ & TNF-308A \\
\hline \multirow[t]{5}{*}{ Warzocha et $\mathrm{al}^{21}$} & 1998 & Caucasian & 76 & 197 & $\mathrm{NHL}$ & PFS & $1.96(1.4,2.73)$ & TNF/LT- $\alpha$ \\
\hline & & Caucasian & 76 & 197 & $\mathrm{NHL}$ & OS & $2.08(1.26,3.43)$ & TNF/LT- $\alpha$ \\
\hline & & Caucasian & 42 & 84 & DLBCL & PFS & $2.33(1.17,4.64)$ & TNF/LT- $\alpha$ \\
\hline & & Caucasian & 42 & 84 & DLBCL & OS & $1.92(0.63,5.80)$ & TNF/LT- $\alpha$ \\
\hline & & Caucasian & 18 & 78 & $\mathrm{FL}$ & PFS & $3.08(2.1,4.52)$ & TNF/LT- $\alpha$ \\
\hline Seidemann et a $\left.\right|^{30}$ & 2005 & Caucasian & 74 & 137 & $\mathrm{BCL}$ & PEFS & $2.34(1.01,5.43)$ & TNF/LT- $\alpha$ \\
\hline Habermann et $\mathrm{al}^{31}$ & 2008 & Caucasian & 121 & 244 & DLBCL & OS & $\mathrm{I} .44(0.95,2.18)$ & TNF-308A \\
\hline
\end{tabular}

Abbreviations: BCL, B-cell lymphomas; $\mathrm{Cl}$, confidence interval; DLBCL, diffuse large B-cell lymphomas; FL, follicular lymphomas; HR, hazard ratio; LT- $\alpha$, lymphotoxin- $\alpha$; NHL, non-Hodgkin lymphoma; OS, overall survival; pEFS, probability of event-free survival; PFS, progression-free survival; TNF, tumor necrosis factor.

Hosgood et $\mathrm{al}^{23}$ and Morton et $\mathrm{al}^{28}$ were identified as outliers in the outcomes of NHL, DLBCL, and BCL. Publication bias was evaluated using Egger's test and funnel plots, and obvious asymmetry was detected only in the recessive and homozygous models of FL.

\section{Prognosis analysis}

\section{Characteristics of five pooled studies}

We collected the data of five studies,,${ }^{9,20,21,30,31}$ including 1,192 patients with NHL to analyze the correlation of TNF308A with the survival outcomes in patients with NHL. Three studies evaluated the independent prognostic role of TNF-308A (the presence of one or more mutant alleles), and another two studies assessed TNF-308/LT- $\alpha+252$ polymorphic high-producer alleles (at least two variant alleles). The progression-free survival (PFS) was reported as a survival outcome in three studies, overall survival (OS) in three studies, and probability of event-free survival in one study. The characteristics of the five studies are shown in Table 3.

\section{TNF-308A and survival outcomes}

The pooled results of five studies, involving 1,192 patients with NHL, suggested that TNF-308A was significantly related to poor OS and PFS in patients with NHL, where the pooled HR was 1.526 (95\% CI: 1.378-1.690, $P<0.001$; Figure 8A) and 1.967 (95\% CI: 1.438-2.689, $P<0.001$; Figure 8B), respectively. Furthermore, the PFS was shorter among patients with BCL with TNF-308A (HR =2.451, 95\% CI: 1.536-3.912, $P<0.001$; Figure 9). The presence of TNF-308A was also associated with worse outcomes in patients with DLBCL (OS: $\mathrm{HR}=1.437,95 \% \mathrm{CI}$ : 1.260-1.638, $P<0.001$; PFS: $\mathrm{HR}=1.555,95 \%$ CI: $1.325-1.826, P<0.001$; Table 4).

\section{Sensitivity analysis and publication bias}

With substantial heterogeneity in the results of PFS in patients with NHL and BCL, the sensitivity analysis was performed to evaluate the influence of single study on the overall estimate, and the study of Osman et al was identified as an outlier. No publication bias was observed except OS in patients with NHL $(P=0.044)$.

\section{Discussion}

The research suggested that TNF-308A could be utilized to identify the potential susceptible population of NHL. ${ }^{36} \mathrm{We}$ extended the previous meta-analyses and reviews to further assess the association of TNF-308A with the risk of NHL in different ethnicities and the source of controls. Our results showed that TNF-308A may be a risk factor of overall NHL, BCL, and DLBCL in Caucasians and healthy population, but not in Asian and hospital population. Besides, the risk of FL was also decreased in the carriers of TNF-308A.

In line with the previous two meta-analyses and reviews, ${ }^{13,14}$ our analysis confirmed the associations of TNF-308G $>$ A with the increased risks of all NHL and BCL in Caucasians and decreased risks in Asians. The different risks of NHL in Caucasians and Asians suggested that ethnic background and genetic structure played a critical role in the susceptibility to NHL. ${ }^{37}$ Contrary to Zhai et al's study, ${ }^{14}$ this significant association was observed only when GA genotype was compared with GG genotype, rather than the additive model (A vs G) in the recent one, which may be explained by the fact that AA genotype of TNF-308 was unlikely to influence the risk of NHL, as indicated in a pooled analysis. ${ }^{13}$ Besides, there was no significant association between TNF-308G $>$ A and the decreased risk of DLBCL in Asians, which was consistently reported in the previous two meta-analyses. ${ }^{13,14}$ It is possible 


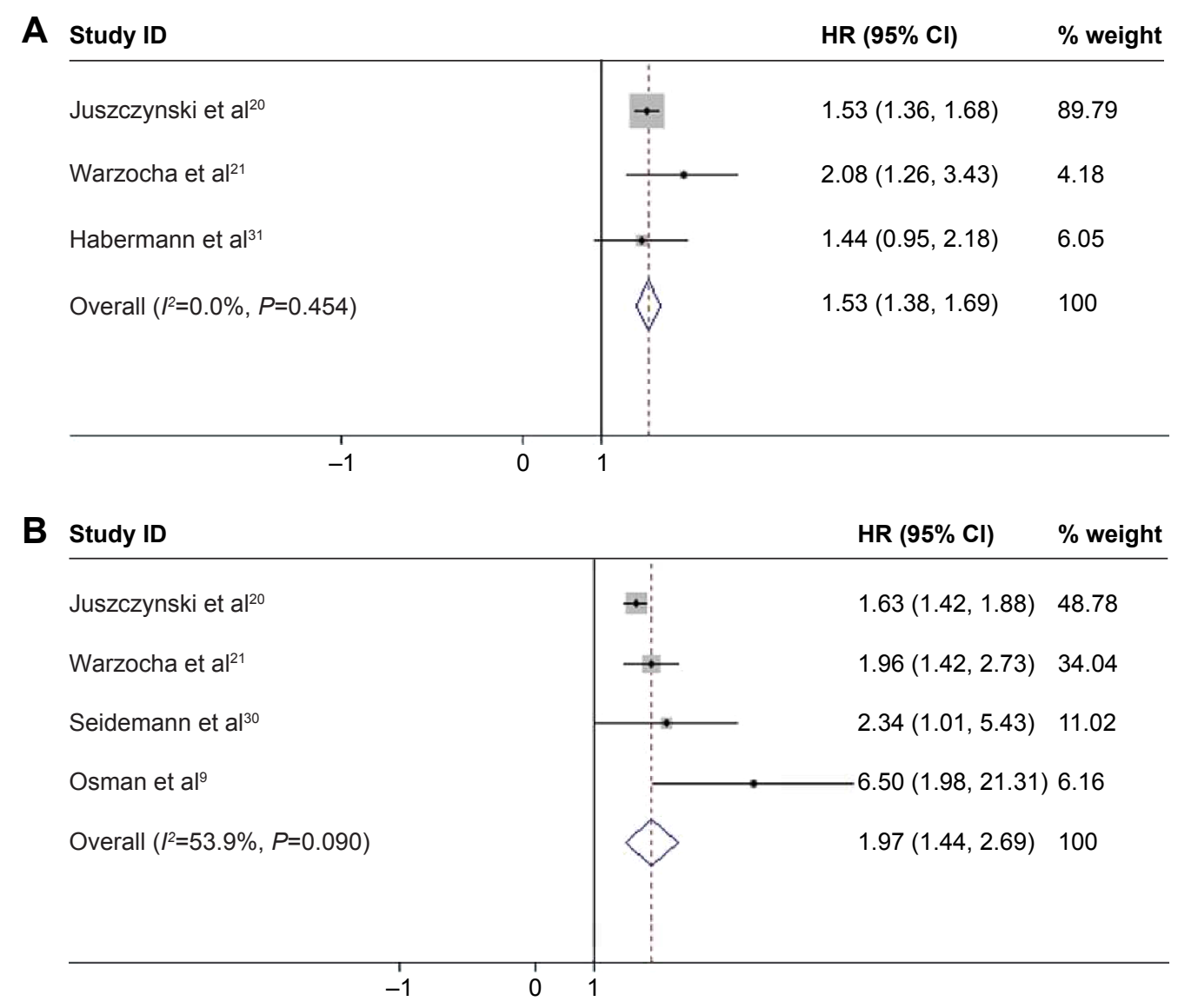

Figure 8 Association between TNF-308A and the progression-free survival and overall survival in patients with NHL.

Notes: (A) Progression-free survival. (B) Overall survival. Weights are from random effects analysis.

Abbreviations: $\mathrm{Cl}$, confidence interval; HR, hazard ratio; NHL, non-Hodgkin lymphoma; TNF, tumor necrosis factor.

that the substantial heterogeneity among Asian subgroups makes it insignificant in our meta-analysis.

Contrary to the previous results of meta-analysis, our results showed that TNF-308G $>$ A reduced the risks of FL among 1,559 cases and 10,669 controls. However, the previous meta-analysis, based on the data of eight studies from the International Lymphoma Epidemiology Consortium, suggested that no significant association was detected between TNF-308G $>$ A and the risk of FL. ${ }^{12}$ Similarly, no pronounced association was observed neither in the extended meta-analysis

\begin{tabular}{|c|c|c|c|}
\hline Study ID & & $\mathrm{HR}(95 \% \mathrm{Cl})$ & $\%$ weight \\
\hline Juszczynski et al ${ }^{20}$ & $\rightarrow$ & $1.52(1.29,1.79)$ & 76.98 \\
\hline Warzocha et $\mathrm{al}^{21}$ & 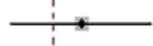 & $2.33(1.17,4.64)$ & 4.40 \\
\hline Seidemann et $\mathrm{al}^{30}$ & & $2.34(1.01,5.43)$ & 2.95 \\
\hline Osman et al ${ }^{9}$ & & $-6.50(1.98,21.31)$ & 1.48 \\
\hline Warzocha et $\mathrm{al}^{21}$ & $\longrightarrow$ & $3.08(2.10,4.52)$ & 14.20 \\
\hline Overall $\left(I^{2}=76.4 \%, P=0.002\right)$ & \langle & $1.77(1.53,2.05)$ & 100 \\
\hline
\end{tabular}

Figure 9 Association between TNF-308A and the PFS in patients with BCL.

Abbreviations: $\mathrm{BCL}$, B-cell lymphomas; $\mathrm{Cl}$, confidence interval; $\mathrm{HR}$, hazard ratio; PFS, progression-free survival; TNF, tumor necrosis factor. 
Table 4 Results of the correlation of TNF-308 with survival outcomes in patients with $\mathrm{NHL}$

\begin{tabular}{|c|c|c|c|c|c|c|c|}
\hline \multicolumn{8}{|c|}{ Sample size } \\
\hline Type & Outcome & $\mathbf{N}$ & $\begin{array}{l}\text { Casel } \\
\text { control }\end{array}$ & $I^{2}$ & $P$-value & HR & $95 \% \mathrm{Cl}$ \\
\hline $\mathrm{NHL}$ & PFS & 4 & $263 / 564$ & 53.90 & $<0.001$ & 1.967 & $(1.438-2.689)$ \\
\hline $\mathrm{NHL}$ & OS & 3 & $250 / 259$ & 0 & $<0.001$ & 1.526 & $(1.378-1.690)$ \\
\hline $\mathrm{BCL}$ & PFS & 4 & $226 / 450$ & 76.4 & $<0.00 \mathrm{I}$ & $2.45 I$ & $(1.536-3.912)$ \\
\hline DLBCL & OS & 3 & $195 / 400$ & 0 & $<0.001$ & 1.437 & $(1.260-1.638)$ \\
\hline DLBCL & PFS & 2 & $74 / 156$ & 28.4 & $<0.001$ & 1.555 & $(1.325-1.826)$ \\
\hline
\end{tabular}

Abbreviations: $\mathrm{BCL}$, $\mathrm{B}$-cell lymphomas; $\mathrm{Cl}$, confidence interval; $\mathrm{DLBCL}$, diffuse large B-cell lymphomas; HR, hazard ratio; N, number of studies; NHL, non-Hodgkin lymphoma; OS, overall survival; PFS, progression-free survival; TNF, tumor necrosis factor.

published in $2010^{13}$ nor in the recent one. ${ }^{14}$ This could largely be attributed to the small number of cases in the previous two studies. Besides, the insignificant association may also be the results of the genetic models used in the recent one in which this association was assessed only in the additive model (A vs G), whereas this correlation was shown in dominant and heterozygous models in the present meta-analysis.

We also performed the subgroup analysis based on the source of controls, which demonstrated a significantly decreased risk of NHL, BCL, and DLBCL in hospital-based studies, whereas increased risk of DLBCL and BCL in population-based studies. The plausible explanation may be that many risk factors of NHL are relatively common in hospital patients, such as smoking, ${ }^{38}$ obesity, ${ }^{39}$ and immune system disease, ${ }^{34}$ compared with healthy population. This contrary conclusion also suggested that the source of controls should be taken into account when the association of TNF-308G $>$ A with the susceptibility to NHL was interpreted. However, the stratified analysis by the source of controls had not been performed in the previous three meta-analyses. ${ }^{12-14}$

According to the results of sensitivity analysis, the studies of Hosgood et $\mathrm{al}^{23}$ and Morton et $\mathrm{al}^{28}$ were identified as outliers in the susceptibility analysis of NHL, BCL, and DLBCL. It is noted that the risk of NHL in Asian populations was contrary to Caucasians. However, the study of Hosgood et al focused on three Asian populations, including Hong Kong, South Korea, and People's Republic of China, which enrolled 2,635 NHL cases and 4,234 controls, while other studies of Asian populations were in smaller numbers. As such, the result of this larger Asian population may be one of the resources of heterogeneity among the pooled population. The control group of Morton et al's study consisted of a small percentage of African-Americans, while the population was mainly Caucasians in the study of Morton et al..$^{28}$ The research showed that the risk of NHL was higher in African-Americans than in other ethnicities. This mixed ethnicity may also be a source of difference in overall outcomes.

In addition to the results of genetic susceptibility to TNF$308 \mathrm{G}>\mathrm{A}$, we examined the potential correlation between TNF-308A and the survival outcome in patients with NHL, which had not been examined in the previous meta-analyses. The PFS and OS were shorter in patients with NHL with TNF-308A, based on the data of 1,192 patients with NHL. Besides, the present results indicated that TNF-308A was a risk factor for the survival outcome in patients with BCL and DLBCL. Consistent with the study of Cerhan et al,,$^{32}$ no significant association of TNF-308A with survival was detected in patients with FL in the study of Warzocha et al. ${ }^{21}$

Lymphotoxin- $\alpha$ (LTA) $252 \mathrm{~A}>\mathrm{G}$ was in linkage disequilibrium with TNF-308G $>$ A, which led to the inseparable effect of survival in the studies of Seidemann et $\mathrm{al}^{30}$ and Warzocha et al. ${ }^{21}$ Both of the studies suggested that the highrisk haplotype (the presence of two or more alleles, either TNF-A or LTA- $\alpha$ ) was associated with poorer survival outcome (Table 4). Nevertheless, previous studies indicated that TNF-308 is the primary contributor of worse survival outcome of patients with NHL, and its association with LTA 252 was insignificant. ${ }^{40}$ Therefore, we may conclude that the presence of TNF-308A is a predictor of worse prognosis of NHL.

According to the results of sensitivity analysis of survival outcomes, hazard ratio (HR) was much higher than the HR in the other four studies in the study of Osman et al. ${ }^{9}$ It is likely that this higher risk leads to the substantial heterogeneity exhibited in the result of PFS in NHL and BCL.

\section{Limitations and future directions}

We searched only six databases for all available full texts and failed to include all the studies from the International Lymphoma Epidemiology Consortium due to the unavailable access to full text, which had been repeatedly used in the previous meta-analyses. Besides, the less common histological subtypes were reported in few studies, limiting the statistical power of pooled estimated OR and hindering a more thorough interpretation of the associations between TNF-308G $>$ A and NHL subtypes. Moreover, we acknowledged that the population selection bias may exist in our study, with only Asians and Caucasians in the susceptibility analysis and Caucasians in prognosis analysis. Finally, only five studies were included to evaluate the correlation of TNF-308G $>$ A and NHL survival. It is hard to exclude the possibility that this correlation may become insignificant after pooling the results of more studies. 
Future expanded studies that would investigate the correlation of TNF-308 with other rare NHL subtypes may be warranted. Similarly, future efforts are also needed to assess the role of TNF-308A with the risk of NHL in larger Asian and African populations. Considering the small number of prognosis analyses, future studies that would explore the prognosis value of TNF-308 in patients with NHL may further refine our current outcomes.

\section{Conclusion}

Overall, our study found that TNF-308G $>$ A polymorphism was associated not only with increased risks of NHL, BCL, and TCL and decreased risk of FL but also with shorter PFS and OS in patients with NHL, BCL, and DLBCL. However, those associations varied among different ethnicities and the source of controls, in which increased risk of NHL, BCL, and DLBCL was observed in Caucasians, whereas decreased risk of NHL and BCL in Asians. Meanwhile, the risk of NHL, BCL, and DLBCL was decreased in hospital-based population, while the risk of BCL and DLBCL was increased in population-based studies. Future studies focused on other NHL subtypes, and ethnicity groups may further our understanding of the association of TNF-308 with the susceptibility to and prognosis of NHL and its subtypes.

\section{Acknowledgments}

This work was supported by the Chinese National 973 Project (2012CB966904 and 20110402), the National Natural Science Foundation of People's Republic of China (81301689 and 81202958), the Yangfan Project of Shanghai Science and Technology Commission (14YF1412300), the Outstanding Youth Training Program of Tongji University (1501219080), and the Shanghai Tenth People's Hospital Climbing Training Program (04.01.13024).

\section{Disclosure}

The authors report no conflicts of interest in this work.

\section{References}

1. Muller AM, Ihorst G, Mertelsmann R, Engelhardt M. Epidemiology of non-Hodgkin's lymphoma (NHL): trends, geographic distribution, and etiology. Ann Hematol. 2005;84(1):1-12.

2. Jemal A, Bray F, Center MM, Ferlay J, Ward E, Forman D. Global cancer statistics. CA Cancer J Clin. 2011;61(2):69-90.

3. Torre LA, Bray F, Siegel RL, Ferlay J, Lortet-Tieulent J, Jemal A. Global cancer statistics, 2012. CA Cancer J Clin. 2015;65(2):87-108.

4. Alexander DD, Mink PJ, Adami HO, et al. The non-Hodgkin lymphomas: a review of the epidemiologic literature. Int J Cancer. 2007;120(suppl 12): $1-39$.

5. Cerhan JR, Fredericksen ZS, Wang AH, et al. Design and validity of a clinic-based case-control study on the molecular epidemiology of lymphoma. Int J Mol Epidemiol Genet. 2011;2(2):95-113.
6. Wang SS, Cerhan JR, Hartge P, et al. Common genetic variants in proinflammatory and other immunoregulatory genes and risk for nonHodgkin lymphoma. Cancer Res. 2006;66(19):9771-9780.

7. Cerhan JR, Wen LM, Fredericksen ZS, et al. Genetic variation in TNF and the NF- $\kappa$ B canonical pathway and risk of non-Hodgkin lymphoma. Cancer Epidemiol Biomarkers Prev. 2008;17(11):3161-3169.

8. Bazzoni F, Beutler B. The tumor necrosis factor ligand and receptor families. N Engl J Med. 1996;334(26):1717-1725.

9. Osman NF, Holyoake T, Zeineldin A, Elkordy AA, McQuaker IG. TNF polymorphisms independently predict outcome in patients with B-cell non-Hodgkin's lymphoma. Iran J Cancer Prev. 2009;2(1):19-27.

10. Wang SS, Cozen W, Cerhan JR, et al. Immune mechanisms in nonHodgkin lymphoma: joint effects of the TNF G308A and IL10 T3575A polymorphisms with non-Hodgkin lymphoma risk factors. Cancer Res. 2007;67(10):5042-5054.

11. Stanulla M, Schrauder A, Welte K, Schrappe M. Tumor necrosis factor and lymphotoxin-alpha genetic polymorphisms and risk of relapse in childhood B-cell precursor acute lymphoblastic leukemia: a casecontrol study of patients treated with BFM therapy. BMC Blood Disord. 2001;1:2.

12. Rothman N, Skibola CF, Wang SS, et al. Genetic variation in TNF and IL10 and risk of non-Hodgkin lymphoma: a report from the InterLymph Consortium. Lancet Oncol. 2006;7(1):27-38.

13. Skibola CF, Bracci PM, Nieters A, et al. Tumor necrosis factor (TNF) and lymphotoxin-alpha (LTA) polymorphisms and risk of non-Hodgkin lymphoma in the InterLymph Consortium. Am J Epidemiol. 2010; 171(3):267-276.

14. Zhai K, Ding J, Zhou Y. Different role of tumor necrosis factor-alpha polymorphism in non-Hodgkin lymphomas among Caucasian and Asian populations: a meta-analysis. Int J Mol Sci. 2014;15(5):7684-7698.

15. Stewart DA. Annual meeting of the Non-Hodgkin's lymphoma presentations from the 46th American Society of Hematology (ASH). Landmarks. 2005;4(10):10-13.

16. Bel Hadj Jrad B, Chatti A, Laatiri A, et al. Tumor necrosis factor promoter gene polymorphism associated with increased susceptibility to non-Hodgkin's lymphomas. Eur J Haematol. 2007;78(2):117-122.

17. Nasiri H, Farajnia S, Rezamand A, et al. Genetic variations of tumor necrosis factor $-\alpha-308$ and lymphtoxin- $\alpha+252$ in non-Hodgkin lymphoma and acute lymphoblastic leukemia patients. Iran J Basic Med Sci. 2013;16(9):991-995.

18. Cerhan JR, Liu-Mares W, Fredericksen ZS, et al. Genetic variation in tumor necrosis factor and the nuclear factor-KB canonical pathway and risk of non-Hodgkin's lymphoma. Cancer Epidemiol Biomarkers Prev. 2008;17(11):3161-3169.

19. Liu J, Liu J, Song B, et al. Genetic variations in CTLA-4, TNF-a, and LTA and susceptibility to T-cell lymphoma in a Chinese population. Cancer Epidemiol. 2013;37:930-934.

20. Juszczynski P, Kalinka E, Bienvenu J, et al. Human leukocyte antigens class II and tumor necrosis factor genetic polymorphisms are independent predictors of non-Hodgkin lymphoma outcome. Blood. 2002; 100(8):3037-3040.

21. Warzocha K, Ribeiro P, Bienvenu J, et al. Genetic polymorphisms in the tumor necrosis factor locus influence non-Hodgkin's lymphoma outcome. Blood. 1998;91(10):3574-3581.

22. Xiao H, Zhang K. Genetic polymorphisms of tumor necrosis factoralpha and lymphotoxin-alpha in Chinese patients with non-Hodgkin lymphoma. Ann Hematol. 2011;90(6):725-727.

23. Hosgood HD, Au WY, Kim HN, et al. IL10 and TNF variants and risk of non-Hodgkin lymphoma among three Asian populations. Jpn Soc Hematol. 2013;97:793-799.

24. Gu X, Shen Y, Fu L, et al. Polymorphic variation of inflammation-related genes and risk of non-Hodgkin lymphoma for Uygur and Han Chinese in Xinjiang. Asian Pacific J Cancer Prev. 2014;15(21):9177-9183.

25. Fernberg P, Chang ET, Duvefelt K, et al. Genetic variation in chromosomal translocation breakpoint and immune function genes and risk of non-Hodgkin lymphoma. Cancer Causes Control. 2010;21: 759-769. 
26. Spink CF, Keen LJ, Mensah FK, GR Law, JL Bidwell, GJ Morgan. Association between non-Hodgkin lymphoma and haplotypes in the TNF region. Br J Haematol. 2006;133:293-300.

27. Ibrahima A, Abdel Rahman H, Khorshied M, Sami R, Nasr N, Khorshid O. Tumor necrosis factor alpha-308 and Lymphotoxin alpha+252 genetic polymorphisms and the susceptibility to non-Hodgkin lymphoma in Egypt. Leuk Res. 2012;36:694-698.

28. Morton LM, Wang SS, Cozen W, et al. Etiologic heterogeneity among non-Hodgkin lymphoma subtypes. Blood. 2008;112:5150-5160.

29. Purdue MP, Lan Q, Kricker A, et al. Polymorphisms in immune function genes and risk of non-Hodgkin lymphoma: findings from the New South Wales non-Hodgkin Lymphoma Study. Carcinogenesis. 2007;28(3): 704-712.

30. Seidemann K, Zimmermann M, Book M, et al. Tumor necrosis factor and lymphotoxin alfa genetic polymorphisms and outcome in pediatric patients with non-Hodgkin's Lymphoma: results from Berlin-FrankfurtMunster Trial NHL-BFM 95. J Clin Onol. 2005;23(33):8414-8421.

31. Habermann TM, Wang SS, Maurer MJ, et al. Host immune gene polymorphisms in combination with clinical and demographic factors predict late survival in diffuse large B-cell lymphoma patients in the pre-rituximab era. Blood. 2008;112(7):2694-2702.

32. Cerhan JR, Wang S, Maurer MJ, et al. Prognostic significance of host immune gene polymorphisms in follicular lymphoma survival. Blood. 2007;109(12):5439-5446.

33. Bi X, Zheng T, Lan Q, et al. Genetic polymorphisms in IL10RA and TNF modify the association between blood transfusion and risk of non-Hodgkin lymphoma. Am J Hematol. 2012;87(8):766-769.
34. Wang SS, Vajdic CM, Linet MS, et al. Associations of Non-Hodgkin Lymphoma (NHL) risk with autoimmune conditions according to putative NHL loci. Am J Epidemiol. 2015;181(6):406-421.

35. Aissani B, Ogwaro KM, Shrestha S, et al. The major histocompatibility complex conserved extended haplotype 8.1 in AIDS-related non-Hodgkin lymphoma. J Acquir Immune Defic Syndr. 2009;52(2):170-179.

36. Skibola CF, Curry JD, Nieters A. Genetic susceptibility to lymphoma. Haematol/Hematol J. 2007;92(7):960-969.

37. Lan Q, Shen M, Garcia-Rossi D, et al. Genotype frequency and F ST analysis of polymorphisms in immunoregulatory genes in Chinese and Caucasian populations. Immunogenetics. 2007;59(11):839-852.

38. Morton LM, Hartge P, Holford TR, et al. Cigarette smoking and risk of non-Hodgkin lymphoma: a pooled analysis from the international lymphoma epidemiology consortium (interlymph). Cancer Epidemiol Biomarkers Prev. 2005;14(4):925-933.

39. Willett EV, Morton LM, Hartge P, et al. Non-Hodgkin lymphoma and obesity: a pooled analysis from the InterLymph consortium. Int J Cancer. 2008;122(9):2062-2070.

40. Nowak J, Kalinka-Warzocha E, Juszczyński P, et al. Haplotype-specific pattern of association of human major histocompatibility complex with non-Hodgkin's lymphoma outcome. Tissue Antigens. 2008; 71(1):16-26.
OncoTargets and Therapy

\section{Publish your work in this journal}

OncoTargets and Therapy is an international, peer-reviewed, open access journal focusing on the pathological basis of all cancers, potential targets for therapy and treatment protocols employed to improve the management of cancer patients. The journal also focuses on the impact of management programs and new therapeutic agents and protocols on

\section{Dovepress}

patient perspectives such as quality of life, adherence and satisfaction The manuscript management system is completely online and includes a very quick and fair peer-review system, which is all easy to use. Visit http://www.dovepress.com/testimonials.php to read real quotes from published authors. 